\title{
Study on Fermentation Kinetics for Accelerated Production of Bioethanol from Glucose, Sucrose and Molasses
}

\section{Betina Tabah ${ }^{1}$, Indra Neel Pulidindi ${ }^{1}$ and Aharon Gedanken ${ }^{1,2 *}$}

${ }^{1}$ Department of Chemistry and Bar-llan Institute of Nanotechnology and Advanced Materials (BINA), Bar-Ilan University, Ramat-Gan 52900, Israel ${ }^{2}$ National Cheng Kung University, Department of Materials Science and Engineering, Tainan 70101, Taiwan

\begin{abstract}
Currently, fermentation is the only available pathway for converting carbohydrates to ethanol and it is often time-consuming. The focus of the current research is to expedite ethanol production from carbohydrates using Saccharomyces cerevisiae. This study evaluated fermentation using a high-speed stirrer (ultraturrax) where glucose was the model carbohydrate. The reaction kinetics of fermentation was evaluated using ${ }^{13} \mathrm{C}$ NMR spectroscopy. The effect of stirring speed on the kinetics of glucose fermentation was studied and two times enhancement in the rate of fermentation was observed using an ultraturrax $\left(3.80 \pm 0.40 \times 10^{-5} \mathrm{~s}^{-1}\right)$ compared to the incubation $\left(1.90 \pm 0.71 \times 10^{-5}\right.$ $\mathrm{s}^{-1}$ ) at $30^{\circ} \mathrm{C}$. The acceleration of the fermentation was also observed using other carbohydrates such as sucrose and molasses. We report the effect of varying a few parameters such as: stirring speed, the effect of shelf-life of yeast, $\mathrm{pH}$ of the broth, and effect of activated carbon on the fermentation kinetics. The optimum $\mathrm{pH}$ range for the fermentation reaction was found to be 4-6.8. Yeast with a six-month shelf-life was found to slow down the fermentation reaction by 5.6 times relative to fresh yeast (up to one month). Our results indicate an efficient method for bioethanol production from carbohydrates.
\end{abstract}
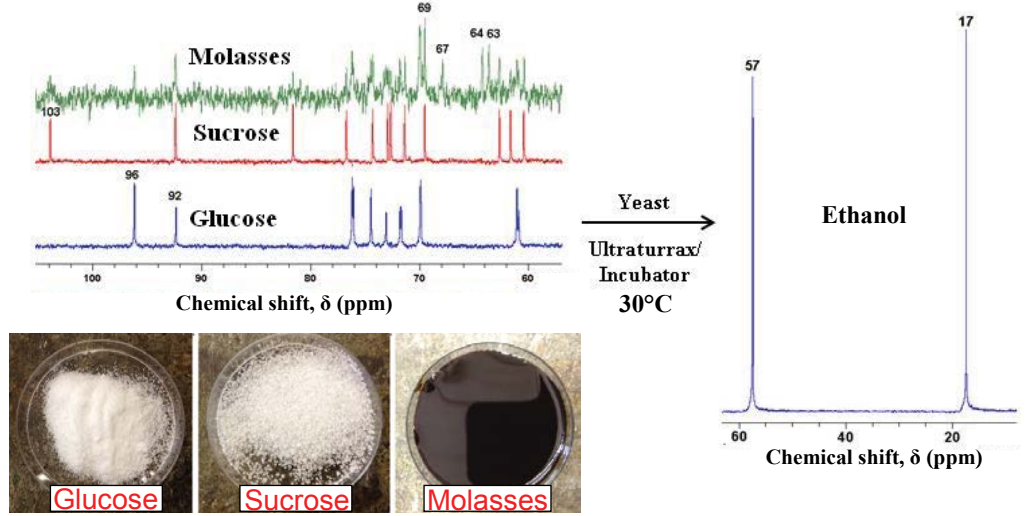

Keywords: Biofuel; Bioethanol; Fermentation; Saccharomyces cerevisiae; Ultraturrax

\section{Introduction}

Worldwide decrease in the major sources of fossil fuels has been a cause of concern. With the depletion of these fuels, efforts are being directed to renewable sources such as solar, wind, and biomass [1]. Bioethanol is regarded as potential biofuel from renewable sources. Bioethanol is widely recognized as one of the most unique transportation fuels with powerful economic, environmental, and strategic benefits [2]. High octane value and high combustion efficiency makes bioethanol one of the most promising alternatives to conventional transportation fuels. Furthermore, bioethanol is carbon neutral and the use of it as a transport fuel can reduce $\mathrm{CO}_{2}$ buildup $[3,4]$. Apart from fuel applications, production of bioethanol is increasing every year because of its use in medicine, cosmetics, and industrial materials [5]. Firstgeneration bioethanol is already being used as a transportation fuel in Brazil and is blended into petroleum in the US [6]. Second-generation bioethanol from lingo-cellulosic materials is still under research or demonstration stage [7].

The conversion of biomass to ethanol includes two processes: the degradation of starting plant material into fermentable sugars (hydrolysis) and the conversion of sugar into alcohol (fermentation)
[8]. Fermentation is a crucial stage in bioethanol production where selection of suitable feedstock for fermentable sugars is a challenge. Homogenous crop materials are easily metabolized to sugars (e.g. molasses from sugar cane, starch from corn kernels) [8,9]. However, fuel-ethanol production from lignocellulosic materials is complicated due to the recalcitrant nature of the molecules present in these materials. In order to make cellulose and hemicellulose more accessible to the catalytic site, a pretreatment is required [10].

Bioethanol production using various bacteria (Clostridium sp.) or yeasts (Saccharomyces sp., Zymomonas sp.) has been studied intensively over the past two decades [11]. One of the most effective

*Corresponding author: Aharon Gedanken, Department of Chemistry and Bar-Ilan Institute of Nanotechnology and Advanced Materials (BINA), Bar-Ilan University, Ramat-Gan 52900, Israel, Tel: +972-3-531-8315; Fax: +972-3-7384053; E-mail: gedanken@mail.biu.ac.il

Received May 20, 2015; Accepted June 23, 2015; Published June 29, 2015

Citation: Tabah B, Pulidindi IN, Gedanken A (2015) Study on Fermentation Kinetics for Accelerated Production of Bioethanol from Glucose, Sucrose and Molasses. J Bioprocess Biotech 5: 232 doi:10.4172/2155-9821.1000232

Copyright: $\odot 2015$ Tabah B, et al. This is an open-access article distributed unde the terms of the Creative Commons Attribution License, which permits unrestricted use, distribution, and reproduction in any medium, provided the original author and source are credited. 
ethanol-producing microorganisms for hexose sugars (e.g. glucose, mannose, and galactose) is the yeast Saccharomyces cerevisiae which has high ethanol productivity, high tolerance to ethanol, and tolerance to inhibitory compounds present in the hydrolysate of lignocellulosic biomass. Native strains of Saccharomyces cerevisiae are unable to utilize xylose for growth or fermentation. Some yeast strains have been reported to ferment xylose into ethanol, but the rate and yield of ethanol production are considerably low compared to their glucose fermentation [12].

Several studies were focused on overcoming the limitations in practical bioethanol production. Wargacki et al. [13] engineered a microorganism (Vibrio splendidus) capable of metabolizing alginate, the major polysaccharide in brown algae, and Takeda et al. [14] developed a bacterial strain (Sphingomanas sp. A1) that could assimilate alginate in brown algae. The utilization of wide variety of feedstock has also been of immense scientific interest. Wang et al. [15] demonstrated the technical and economical feasibility of bioethanol production from waste paper. Rapeseed straw, oil-palm fronds, and wheat straw were recently used for bioethanol production and they yielded $39.9 \mathrm{~g} / \mathrm{L}$, $18.2 \mathrm{~g} / \mathrm{L}$ and $14.0 \mathrm{~g} / \mathrm{L}$ of ethanol, respectively, under optimal reaction conditions [16-18].

Currently, there is only one available pathway for the conversion of carbohydrates into ethanol, i.e., the biological pathway which is often time-consuming. Ultraturrax is a high-speed stirrer that could generate cavitation, collision, sheer and impact which in turn causes dispersion, homogenization, emulsification and disintegration of particles in the reaction medium. The potential of the device is used for the first time for bioethanol production in this study. There have been recent reports on the acceleration of delignification, enzymatic hydrolysis and fermentation using sonication technique. Pulidindi et al. [19] reported 2.3 times acceleration in the rate of the fermentation of glucose after exposure to soft sonication. Subhedar and Gogate [20] reported two times increase in the delignification of waste newspaper in an ultrasound assisted alkali pretreatment. 2.4 times increase in the release of reducing sugars from waste newspaper was also reported using ultrasound assisted enzymatic hydrolysis of waste newspaper [21]. Ofori-Boateng and Lee [17] reported four times higher bioethanol yield and shorter reaction time in sonication assisted simultaneous saccharification and fermentation (SSF) of oil palm fronds compared to a non-sonication SSF process. Korzen [22] reported bioethanol yield of $6.2 \mathrm{wt} . \%$ (dry weight basis) in $3 \mathrm{~h}$ from SSF of Ulva rigida using sonication compared to $4.9 \mathrm{wt} . \%$ yield in incubator for $48 \mathrm{~h}$.

The focus of the current research is to evaluate different carbohydrates and fermentation conditions for accelerated bioethanol production. In the present study, ethanol production was performed with ultraturrax device using glucose as a model carbohydrate. In addition to glucose, the feasibility of sucrose and molasses as carbon sources for the production of bioethanol was also evaluated.

\section{Materials and Methods}

\section{Fermentation conditions}

For all experiments, fermentation was performed with Saccharomyces cerevisiae, commercial Baker's yeast bought from the supermarket. The substrate D-Glucose was obtained from SigmaAldrich and molasses and sucrose were obtained from the supermarket. The activated carbon (Activated charcoal Norit ${ }^{\circledR}$ ) was purchased from Sigma-Aldrich. Fermentation reactions were performed in 250 $\mathrm{mL}$ Erlenmeyer flasks and the flasks were closed with cotton plugs.
The fermentation broth for both glucose and sucrose fermentation comprised $20 \mathrm{~g}$ (or $40 \mathrm{~g}$ for the $40 \mathrm{wt} . \%$ solution) of glucose or sucrose dissolved in $100 \mathrm{~mL}$ of water to which $2 \mathrm{~g}$ (or $4 \mathrm{~g}$ for the $40 \mathrm{wt} . \%$ solution) of yeast was added. For molasses fermentation, the broth comprised $10 \mathrm{~g}$ molasses dissolved in $100 \mathrm{~mL}$ of water with $1 \mathrm{~g}$ of yeast. As control experiments, the fermentation reactions were performed in an incubator (MRC, LM-570, orbital shaker incubator) without shaking. To evaluate the effect of stirring speed on fermentation, the flasks were placed in a high-speed stirrer ultraturrax device (Leroy Somer, Digidrive SK, make ESCO-LABOR) at $30^{\circ} \mathrm{C}$.

\section{${ }^{13} \mathrm{C}$ NMR analysis}

The kinetics of fermentation reactions were studied using ${ }^{13} \mathrm{C}$ NMR spectroscopy (Supplementary data Section 1). Aliquots were collected from fermentation broths at regular time intervals and analyzed by ${ }^{13} \mathrm{C}$ NMR spectroscopy. ${ }^{13} \mathrm{C}$ NMR spectra were recorded on Bruker Avance DPX 300. $\mathrm{D}_{2} \mathrm{O}$ was used as a solvent.

\section{${ }^{1} \mathrm{H}$ NMR analysis}

${ }^{1} \mathrm{H}$ NMR spectroscopy was used for the quantification of ethanol produced in glucose fermentation (Supplementary data section 1.2). Aliquots were collected from the fermentation broth at regular time intervals and analyzed by ${ }^{1} \mathrm{H}$ NMR spectroscopy. $\mathrm{D}_{2} \mathrm{O}$ was used as a solvent and HCOONa was used as an internal standard. ${ }^{1} \mathrm{H}$ NMR spectra were recorded on Bruker Avance DPX 300.

\section{Results and Discussion}

\section{Effect of stirring speed on the rate of glucose fermentation}

Glucose (20 wt.\%) fermentation was performed using ultraturrax at different stirring speeds. Mechanical stirring was found to have an accelerating effect on the rate of fermentation. Relative to a stand-still reaction in incubator $\left(\mathrm{k}=1.90 \pm 0.71 \times 10^{-5} \mathrm{~s}^{-1}\right)$ or mechanical stirring at $5,000 \mathrm{rpm}\left(\mathrm{k}=1.80 \pm 0.30 \times 10^{-5} \mathrm{~s}^{-1}\right)$, stirring at $10,000 \mathrm{rpm}(\mathrm{k}=3.80 \pm$ $\left.0.40 \times 10^{-5} \mathrm{~s}^{-1}\right)$ showed two times enhancement $\left(\mathrm{k}_{\text {ultraturrax }{ }_{10000}} / \mathrm{k}_{\text {incubator }}=2\right)$ in the reaction rate constant value $\left(\right.$ at $\left.30^{\circ} \mathrm{C}\right)$. Among different stirring speeds tested for $20 \mathrm{wt} \%$ glucose fermentation using the high-speed stirrer ultraturrax, $10,000 \mathrm{rpm}$ was found to be the optimum stirring speed (according to the $\mathrm{k}$ values) since increasing the speed further to $20,000 \mathrm{rpm}\left(\mathrm{k}=4.20 \pm 0.40 \times 10^{-5} \mathrm{~s}^{-1}\right)$ did not double the reaction rate constant. The values of the reaction rate constants $(\mathrm{k})$ as a function of stirring speed are summarized in Table 1.

\section{Monitoring complete glucose fermentation}

Glucose (20 wt.\%) fermentation was monitored until completion. ${ }^{13} \mathrm{C}$ NMR spectra of aliquots collected at regular time intervals from the fermentation broth maintained in the ultraturrax and in the incubator $\left(\right.$ at $30^{\circ} \mathrm{C}$ ) are shown in Figure 1 . As a function of time, the intensity of ethanol peaks (17 and $57 \mathrm{ppm}$ ) increased and the intensity of glucose peaks (60.9 (C6), 69.9 (C4), 71.7 (C2), 74.4 (C3), 76.0 (C5), 92 (C1, $\beta$ ) $96(\mathrm{C} 1, \alpha) \mathrm{ppm})$ decreased. No trace of glucose was observed in $12 \mathrm{~h}$ and $16 \mathrm{~h}$ samples collected from the broth in ultraturrax and incubator, respectively, which indicated the completion of the fermentation

\begin{tabular}{|c|c|}
\hline Stirring speed $(\mathbf{r p m})$ & Reaction rate constant, $\mathbf{k}\left(\mathbf{\times} \mathbf{1 0}^{-\mathbf{5}} \mathbf{s}^{-1}\right)$ \\
\hline 0 & $1.90 \pm 0.71$ \\
\hline 5,000 & $1.80 \pm 0.30$ \\
\hline 10,000 & $3.80 \pm 0.40$ \\
\hline 20,000 & $4.20 \pm 0.40$ \\
\hline
\end{tabular}

Note: $\mathrm{k}$ values are mean \pm standard deviation, replicate no. $n=4$

Table 1: Effect of mechanical stirring on kinetics of glucose fermentation. 
Incubation

$\left(\mathrm{k}=1.90 \pm 0.71 \times 10^{-5} \mathrm{~s}^{-1}\right)$

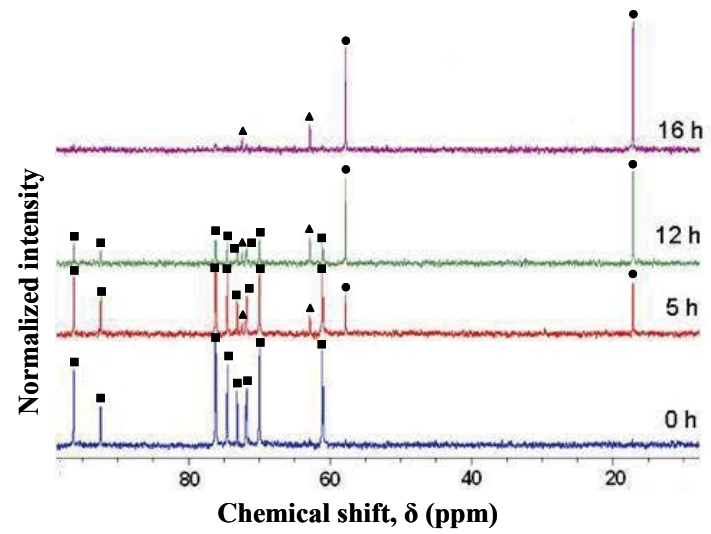

Ultraturrax

$\left(\mathrm{k}=3.80 \pm 0.40 \times 10^{-5} \mathrm{~s}^{-1}\right)$

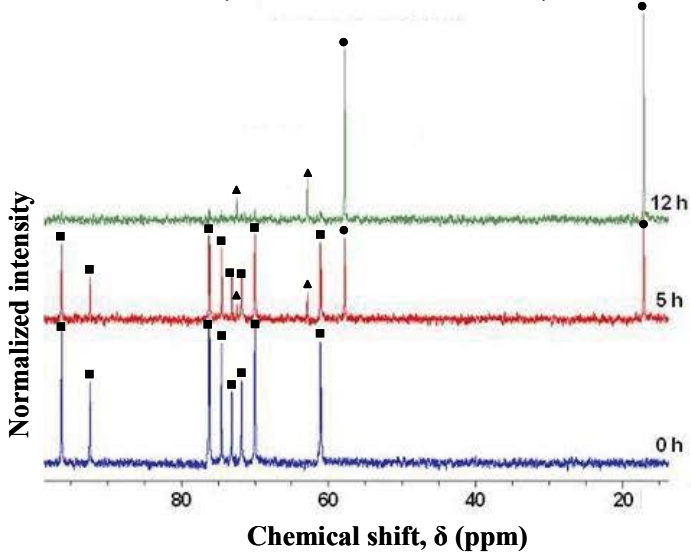

Figure 1: ${ }^{13} \mathrm{C}$ NMR spectra of aliquots from glucose $(20 \mathrm{wt} . \%)$ fermentation broth (maintained in ultraturrax and incubator at $30^{\circ} \mathrm{C}$ ) collected at regular time intervals until completion. The symbol $\boldsymbol{\|}$ shows glucose peaks, $\boldsymbol{\Delta}$ shows glycerol peaks, and $\bullet$ shows ethanol peaks. The ratio of the intensity of peaks of ethanol (at 17 $\mathrm{ppm}$ ) to that of glucose (at $96 \mathrm{ppm}$ ) was used to monitor the reaction kinetics. Reaction rate constant, $\mathrm{k}$, values are mean \pm standard deviation, replicate no. $n=4$.

reaction. As shown in Figure 1, the time required for the completion of the fermentation was reduced from $16 \mathrm{~h}$ (incubation) to $12 \mathrm{~h}$ with the use of the ultraturrax at $10,000 \mathrm{rpm}\left(\right.$ at $\left.30^{\circ} \mathrm{C}\right)$. In addition to ethanol, glycerol (62.8 and $72.3 \mathrm{ppm}$ ) was also formed as a secondary metabolite during the fermentation.

\section{Effect of substrate (glucose) concentration on the rate of fermentation}

In addition to 20 wt.\% glucose fermentation (Figure 1), the fermentation was also performed with $40 \mathrm{wt}$.\% glucose (Supplementary data Figure S1). The objective of the experiment was to verify whether in high glucose concentrations, which usually inhibit yeast performance, the fermentation rate was also accelerated using ultraturrax. Although the substrate concentration was doubled, the reaction rate was almost the same for $20 \mathrm{wt} . \%\left(\mathrm{k}=3.80 \pm 0.40 \times 10^{-5} \mathrm{~s}^{-1}\right)$ and $40 \mathrm{wt} . \%(\mathrm{k}=3.60 \pm 1.16$ $\left.\times 10^{-5} \mathrm{~s}^{-1}\right)$ glucose fermentation. It is known that, ethanol concentration greater than $4 \%$ will have a poisoning effect on yeasts and induces stress by retarding their productivity of further ethanol production [23]. The ratio between the reaction rate constant value $\left(\mathrm{k}_{\text {ultraturrax }}\right.$ ' $\left.\mathrm{k}_{\text {incubator }}\right)$ for the fermentation of glucose (40 wt.\%) in ultraturrax and incubator (at $30^{\circ} \mathrm{C}$ ) was 1.7 (Supplementary data Figure S1) and the glucose conversion after six hours was $69 \%$ in ultraturrax and $47 \%$ in incubator.

\section{Effect of yeast shelf-life on the kinetics of glucose fermentation}

To evaluate the effect of yeast shelf-life on fermentation kinetics, glucose (20 wt.\%) fermentation was performed with fresh (up to one month) as well as old (six months) yeast. The fermentation was performed using ultraturrax at 5,000 rpm and at 10,000 rpm. The rate constant $(\mathrm{k})$ values calculated from each experiment are summarized in Table 2. Using yeast with long shelf-life reduced the fermentation rate. Long shelf-life, nearly six months, was found to decelerate the fermentation rate by almost 3 times and 5.6 times compared to fresh yeast when the stirring speeds were $5,000 \mathrm{rpm}$ and $10,000 \mathrm{rpm}$, respectively. Thus, yeast shelf-life is an important parameter that affects the fermentation rate. Although dry yeast can be stored at room temperature and performs well for the duration of the package shelf-life, it will always lose some of its viability and activity over time.
However, at colder temperatures these losses are less compared to warmer temperatures.

\section{Effect of additives on the glucose fermentation rate}

Additives are known to alter the rate of fermentation of sugars. Several additives have been reported to improve the fermentation characteristics of yeast strains through protection against the inhibitory effects of the substrate and the product. These include unsaturated lipids, soy flour, Aspergillus oryzae proteolipids, skim milk powder, and chitin. Raman et al. [24] accelerated the rate of fermentation of molasses 1.5 times by adding silicate (zeolite) to the fermentation broth.

In the current study, to investigate whether the addition of activated carbon alters the kinetics of fermentation of glucose (20 wt.\%), $2 \mathrm{~g}$ of activated carbon was added to the broth. The effect of additive was studied using ultraturrax. The reaction rate was found to decelerate 1.5 times with the addition of activated carbon to the broth $\left(\mathrm{k}_{\text {without additive }}\right.$ $\left.\mathrm{k}_{\text {with additive }}=3.80 \pm 0.40 \times 10^{-5} \mathrm{~s}^{-1} / 2.60 \pm 0.80 \times 10^{-5} \mathrm{~s}^{-1}\right)$. There was a drastic decrease in $\mathrm{pH}$ (from 6.8 to 2 ) caused by the addition of the activated carbon. To attribute this deceleration in rate to the decrease in $\mathrm{pH}$, the $\mathrm{pH}$ of the broth after the addition of activated carbon was raised to 6.8. At a $\mathrm{pH}$ of 6.8 , in the presence of the additive, the reaction rate was almost the same $\left(\mathrm{k}=3.63 \pm 0.35 \times 10^{-5} \mathrm{~s}^{-1}\right)$ as the reaction rate without any additives $\left(\mathrm{k}=3.80 \pm 0.40 \times 10^{-5} \mathrm{~s}^{-1}\right)$. Thus, the presence of activated carbon had no affect on the rate of glucose fermentation if the $\mathrm{pH}$ remained unaltered, in other words activated carbon did not improve the fermentation rate.

Inherently, due to the presence of surface oxygen-containing functional groups such as $-\mathrm{COOH}$, which are formed as a result of the activation process involved in the production of the carbon material, the activated carbon is acidic. The $\mathrm{pH}$ of the neutral glucose solution ( $\mathrm{pH}=6.7$ ) decreased to 2.2 solely due to the addition of activated carbon which verifies the inherent acidity of activated carbon. Therefore, the decrease in $\mathrm{pH}$ was not due to the presence of the yeast.

\section{Effect of $\mathrm{pH}$ on the kinetics of glucose fermentation}

One of the main factors that have a significant effect on the performance of yeast is the $\mathrm{pH}$. The $\mathrm{pH}$ of the fermentation broth has 
Citation: Tabah B, Pulidindi IN, Gedanken A (2015) Study on Fermentation Kinetics for Accelerated Production of Bioethanol from Glucose, Sucrose and Molasses. J Bioprocess Biotech 5: 232 doi:10.4172/2155-9821.1000232

been varied $(2,4$, and 6.8) using diluted $\mathrm{HCl}$ and $\mathrm{NaOH}$. The kinetics of the fermentation reaction at each $\mathrm{pH}$ value was monitored. The reaction rate constants at a $\mathrm{pH}$ of 2,4 , and 6.8 were calculated as $2.50 \pm 0.74 \times$ $10^{-5} \mathrm{~s}^{-1}, 3.60 \pm 0.60 \times 10^{-5} \mathrm{~s}^{-1}$, and $3.80 \pm 0.40 \times 10^{-5} \mathrm{~s}^{-1}$, respectively, where highly acidic $\mathrm{pH}(=2)$ decelerated the rate of glucose fermentation by two compared to the rate at a $\mathrm{pH}$ of either 4 or 6.8. A pH between 4 and nearly neutral $\mathrm{pH}(=6.8)$ had no significant effect on the fermentation rate. Thus, we report a $\mathrm{pH}$ range of 4-6.8 as the optimum range for glucose fermentation of the yeast Saccharomyces cerevisiae. Lee et al. [25] have reported an optimum $\mathrm{pH}$ value of 6.0 for the fermentation of glucose. Chiang et al. [26] reported a $\mathrm{pH}$ range of 4-6 as an optimum range for the fermentation of $\mathrm{D}$-xylose using commercial Baker's yeast. An optimum $\mathrm{pH}$ range was reported to be 4-5.5 for yeasts other than Saccharomyces cerevisiae as well [27].

\section{Reusability of yeast using an ultraturrax}

To further study whether the yeast can be reused even after exposure to ultraturrax, the yeast was separated from the fermentation broth soon after the complete conversion of glucose $(12 \mathrm{~h})$ into ethanol. The fermentation broth was centrifuged and the supernatant was analyzed for ethanol estimation (using ${ }^{1} \mathrm{H}$ NMR). To remove the traces of ethanol, residual yeast was washed repeatedly with distilled water. The regenerated yeast was used for another cycle of fermentation of glucose (20 wt.\%). The reaction rate using the regenerated yeast was found to be 8 times lower than that of the fresh yeast $\left(\mathrm{k}_{\text {fresh yeast }} / \mathrm{k}_{\text {regenerated }}\right.$ $\left.=3.80 \pm 0.40 \times 10^{-5} \mathrm{~s}^{-1} / 0.47 \pm 0.06 \times 10^{-5} \mathrm{~s}^{-1}\right)$. The lower kinetics may also be due to the loss of some yeast during recycling. However, in industrial bioethanol production, yeast is not regenerated and reused. For every batch of ethanol production, fresh yeast is used. In this study, the reusability was tested to verify that ultraturrax had not damaged the yeast cells. With regenerated yeast, even after $12 \mathrm{~h}$ of ultraturrax exposure, the yield of ethanol was $17 \%$ of the theoretical yield. Even though it is possible to reuse the yeast even after ultraturrax exposure, the reaction rate constant with the regenerated yeast $(\mathrm{k}=0.47 \pm 0.06 \times$ $\left.10^{-5} \mathrm{~s}^{-1}\right)$ is clearly lower than the process performed in an incubator with fresh yeast $\left(\mathrm{k}=1.90 \pm 0.71 \times 10^{-5} \mathrm{~s}^{-1}\right)$. Therefore, the reuse of yeast is not recommended in ultraturrax based fermentation process.

\begin{tabular}{|c|c|c|c|}
\hline Stirring speed (rpm) & Yeast & Reaction rate constant, $\mathrm{k}\left(\times 10^{-5} \mathrm{~s}^{-1}\right)$ & $\mathbf{k}_{\text {fresh }} / \mathbf{k}_{\text {old }}$ \\
\hline \multirow{2}{*}{5,000} & Old & $0.61 \pm 0.10$ & \multirow{2}{*}{2.95} \\
\hline & Fresh & $1.80 \pm 0.30$ & \\
\hline \multirow{2}{*}{10,000} & Old & $0.68 \pm 0.06$ & \multirow{2}{*}{5.60} \\
\hline & Fresh & $3.80 \pm 0.40$ & \\
\hline
\end{tabular}

Note: Fresh yeast indicates short shelf-life (up to one month) whereas old yeast indicates long shelf-life (six months). $\mathrm{k}$ values are mean \pm standard deviation, replicate no. $n=4$.

Table 2: Performance of yeast as a function of shelf-life.

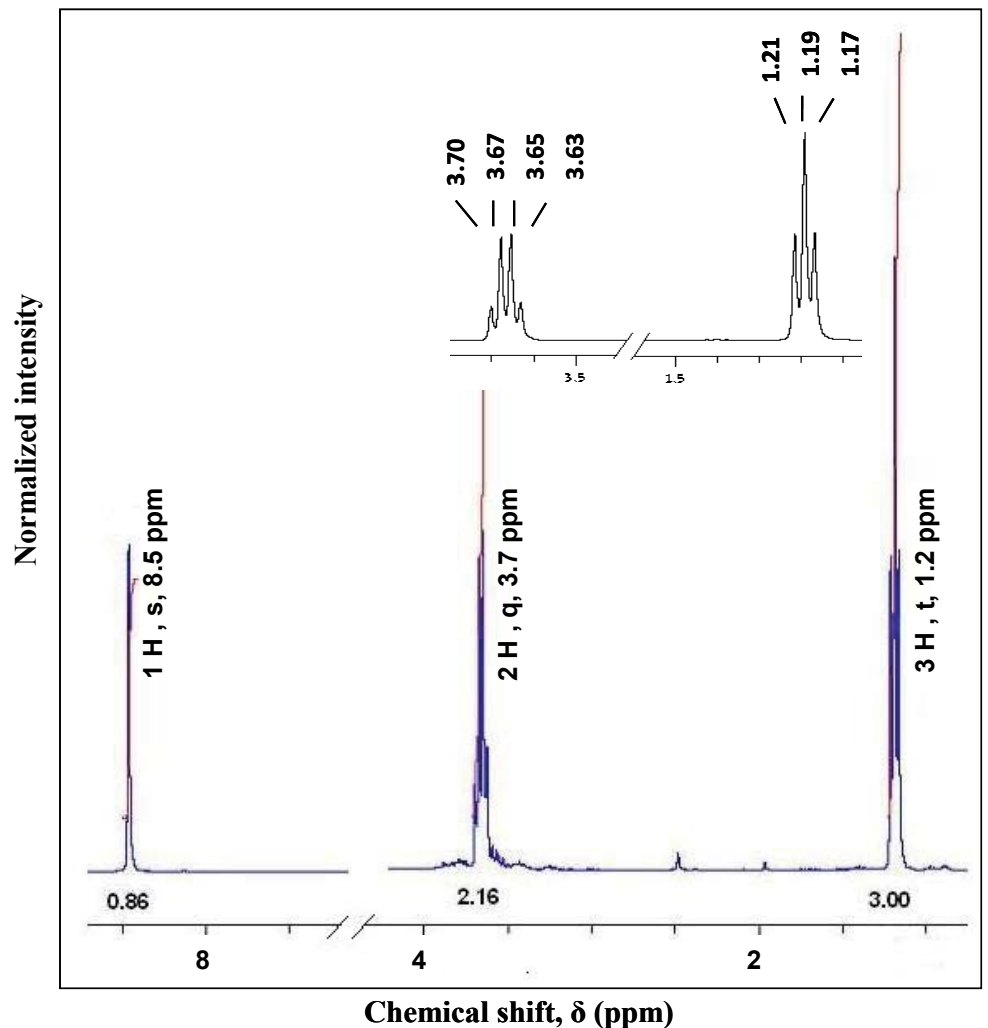

Figure 2: ${ }^{1} \mathrm{H}$ NMR spectrum of an aliquot from glucose $(20 \mathrm{wt} . \%)$ fermentation broth after $12 \mathrm{~h}$ of ultraturrax exposure at $10,000 \mathrm{rpm}, 30^{\circ} \mathrm{C}$. Inset shows the ethanol peaks, a $3 \mathrm{H}(\mathrm{t})$ at $1.2 \mathrm{ppm}$ and a $2 \mathrm{H}(\mathrm{q})$ at $3.7 \mathrm{ppm}$. The singlet peak at $8.5 \mathrm{ppm}$ is the internal standard, $\mathrm{HCOONa}$. 
Citation: Tabah B, Pulidindi IN, Gedanken A (2015) Study on Fermentation Kinetics for Accelerated Production of Bioethanol from Glucose, Sucrose and Molasses. J Bioprocess Biotech 5: 232 doi:10.4172/2155-9821.1000232

\section{Quantification of ethanol from glucose fermentation using ${ }^{1}$ H NMR spectroscopy}

An aliquot from glucose fermentation broth (20 wt.\%) after $12 \mathrm{~h}$ of ultraturrax exposure (after completion of the reaction as depicted in Figure 1) was collected and analyzed by ${ }^{1} \mathrm{H}$ NMR spectroscopy (Figure 2). $\mathrm{A} 3 \mathrm{H}(\mathrm{t})$ at $1.2 \mathrm{ppm}$ and a $2 \mathrm{H}(\mathrm{q})$ at $3.7 \mathrm{ppm}$ are typical of ethanol. The intense singlet peak at $8.5 \mathrm{ppm}$ is typical of HCOONa which was used as an internal standard. The detailed methodology for ethanol quantification is shown in supplementary data section 1.1.

With fresh yeast, complete fermentation of glucose $(20 \mathrm{~g})$ yielded $8.2 \mathrm{~g}$ ethanol. Theoretically, $20 \mathrm{~g}$ glucose should yield $10.2 \mathrm{~g}$ ethanol. The observed ethanol yield, after the complete conversion of glucose using an ultraturrax for $12 \mathrm{~h}$, is $80.4 \%$ of the theoretical yield. The other $19.6 \%$ of the product may be glycerol, an inevitable secondary metabolite, and other byproducts. Moreover, not all glucose in the fermentation broth was consumed for the fermentation by the microorganisms; some of the glucose was also used for the growth and sustenance of the yeast.

\section{Evaluation of kinetics of ethanol production from different carbohydrate feedstock}

Sucrose is a disaccharide of glucose and fructose. Relative to glucose, sucrose as an extract from sugar cane is more readily available. Molasses is a by-product of the cane sugar manufacturing process. Typical molasses comprises sucrose, glucose, and fructose. Industrialgrade ethanol, a key product in the conversion of sugars and starches into energy and chemical feedstocks, is produced in India exclusively through the fermentation of sugarcane molasses using yeasts [24]. In addition to glucose fermentation, the effect of mechanical stirring on sucrose and molasses fermentation was also evaluated. Aliquots from fermentation broths (maintained in ultraturrax at 10,000 rpm and in incubator at $30^{\circ} \mathrm{C}$ ) were collected at regular time intervals and ${ }^{13} \mathrm{C} \mathrm{NMR}$
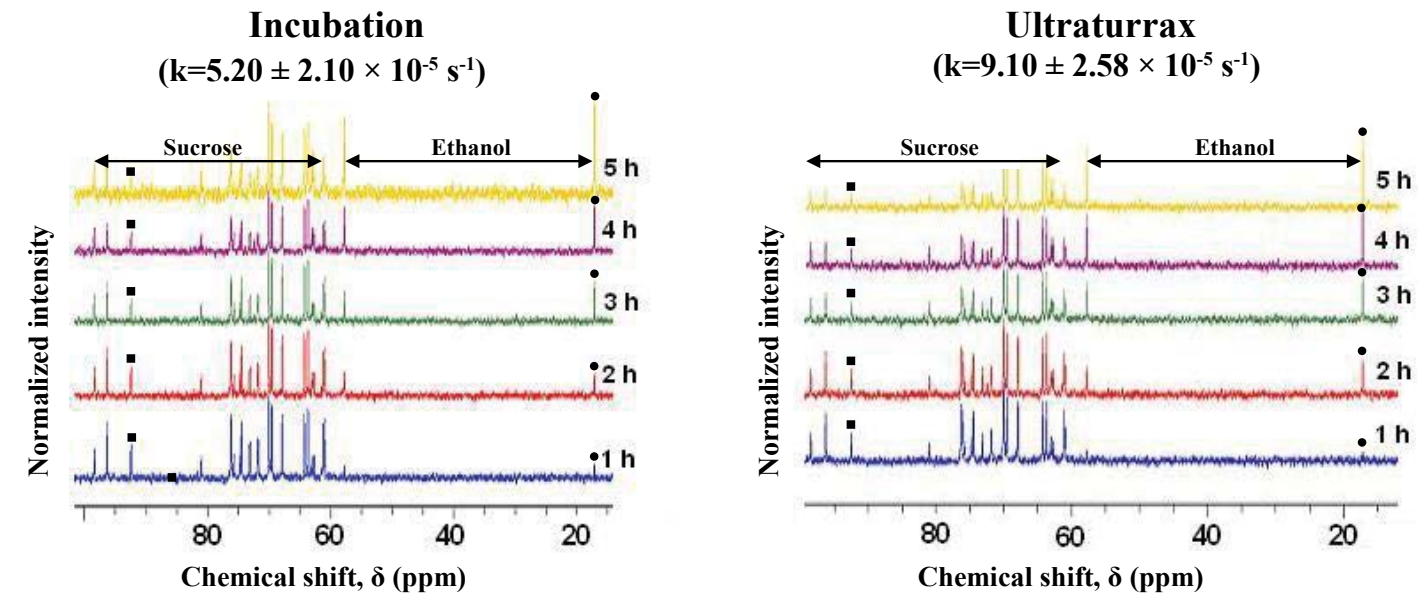

Figure 3: ${ }^{13} \mathrm{C}$ NMR spectra of aliquots from sucrose (20 wt.\%) fermentation broth maintained in incubator and ultraturrax at $30{ }^{\circ} \mathrm{C}$. The peaks between 60 and $100 \mathrm{ppm}$ belong to sucrose and the peaks at 17 and $57 \mathrm{ppm}$ belong to ethanol. The ratio of the intensity of peaks of ethanol (at $17 \mathrm{ppm}$, $\bullet$ ) to that of sucrose (at $92 \mathrm{ppm}, \boldsymbol{\square})$ was used to monitor the reaction kinetics. Reaction rate constant, k, values are mean \pm standard deviation, replicate no. $n=3$.

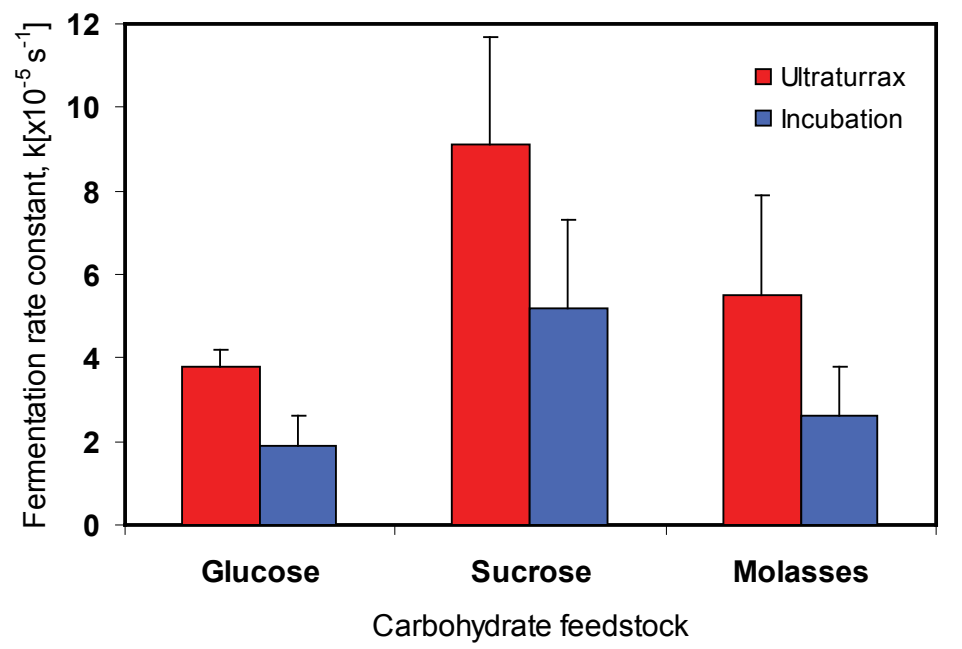

Figure 4: Effect of carbohydrate feedstock (glucose, sucrose, and molasses) on fermentation kinetics (replicate no. $n=3$ for sucrose and molasses and $n=4$ for glucose; error bars indicate standard deviation, SD). 
spectra were recorded (Figure 3 and Supplementary data Figure S2). The effect of mechanical stirring on the fermentation rates of sucrose and molasses is summarized in Table 3 . The accelerating effect of the mechanical stirring by ultraturrax exposure was also dependent on the feedstock. With either sucrose or glucose, a 1.7 times acceleration in reaction rate was observed whereas the acceleration rate was 2.1 times for molasses, which indicated that the acceleration in fermentation was slightly higher in molasses than in glucose and sucrose.

Moreover, the fermentation rate was found to be a function of the feedstock used. The effect of carbohydrate feedstock, such as glucose, sucrose, and molasses, on fermentation kinetics is shown in Figure 4. As depicted in Figure 4, the rate of sucrose fermentation was nearly two times faster than either glucose or molasses regardless of the fermentation method used. According to our results, it is evident that sucrose is an ideal feedstock for the production of ethanol as it was found to be more feasible to be fermented.

D'Amore et al. [28] reported that, in the initial stages of fermentation, sucrose is rapidly hydrolyzed into glucose and fructose by the action of the periplasmic enzyme invertase, prior to the sugars being transported across the cell membrane. Glucose was taken up preferentially over the other hydrolysis product fructose. Growth of Saccharomyces cerevisiae on a medium consisting of a mixture of glucose and fructose also resulted in the preferential uptake of glucose. However, when glucose and fructose were added separately, the uptake profile for each sugar was very similar. Since glucose is a monosaccharide, it is a common misconception that it should provide a higher rate of fermentation as it does not need to be broken down. However, glucose enters the yeast cells by facilitated diffusion which requires carrier proteins. When glucose is being absorbed, there will be a point where the rate reaches its maximum and all the carrier proteins are being used. When sucrose is the substrate, it splits into glucose and fructose. When all the carrier proteins are transporting glucose, different proteins are used for fructose (due to the tertiary structure of the protein), so the composite monosaccharides of sucrose can enter the yeast at a higher rate [28]. Hence, the rate is faster in the case of sucrose fermentation.

\section{Conclusions}

A way to expedite ethanol production from carbohydrates was evaluated in this study. The effect of mechanical stirring (ultraturrax) on the kinetics of fermentation was critically analyzed. In conclusion, nearly two times increment in the reaction rate was observed in the fermentation of glucose, sucrose, and molasses by using a high-speed stirrer. Use of an ultraturrax is suggested as a new method for enhancing the catalytic function of Saccharomyces cerevisiae leading to ethanol production. Thus, an effective, fast, and green method was developed for bioethanol production using renewable feedstocks. Future studies should investigate the use of hydrolyzates from lignocellulosic biomass for bioethanol production using the proposed method.

\section{Acknowledgements}

The authors acknowledge the financial support from the Israel Science Foundation (ISF Grant No. 12/586) and the Ministry of Science and Technology of Israel (MoST Grant No. 3-9802).

\section{References}

1. Pulidindi IN, Gedanken A (2015) Employing novel techniques (Microwave and Sonochemistry) in the synthesis of biodiesel and bioethanol. Production of Biofuels and Chemicals with Ultrasound 4: 159-185.

2. Zhang $W$, Lin $Y$, Zhang Q, Wang $X$, Wu D, et al. (2013) Optimisation of simultaneous saccharification and fermentation of wheat straw for ethanol production. Fuel 112: 331-337.
3. Hasunuma T, Kondo A (2012) Development of yeast cell factories for consolidated bioprocessing of lignocellulose to bioethanol through cell surface engineering. Biotechnol Adv 30: 1207-1218.

4. Subhedar PB, Gogate PR (2013) Intensification of enzymatic hydrolysis of lignocellulose using ultrasound for efficient bioethanol production: A review. Ind Eng Chem Res 52: 11816-11828.

5. Harde SM, Bankar SB, Ojamo H, Granstrom T, Singhal RS, et al. (2014) Continuous lignocellulosic ethanol production using Coleus forskohlii root hydrolysate. Fuel 126: 77-84

6. Pulidindi IN, Kimchi BB, Gedanken A (2014) Can cellulose be a sustainable feedstock for bioethanol production? Renewable Energy 71: 77-80.

7. Tewfik SR, El Defrawy NM, Sorour MH (2013) Liquid fuel resources and prospects for ligno-cellulosic ethanol: An Egyptian case study. Egypt J Pet 22 269-276.

8. Elshahed MS (2010) Microbiological aspects of biofuel production: current status and future directions. J Adv Res 1: 103-111.

9. Nikolic S, Mojovic L, Rakin M, Pejin D, Pejin J (2010) Ultrasound-assisted production of bioethanol by simultaneous saccharification and fermentation of corn meal. Food Chem 122: 216-222.

10. Goncalves FA, Ruiz HA, Nogueira CC, Santos ES, Teixeira JA, et al. (2014) Comparison of delignified coconuts waste and cactus for fuel-ethano production by the simultaneous and semi-simultaneous saccharification and fermentation strategies. Fuel 131: 66-76.

11. Galaction Al, Lupasteanu AM, Cascaval D (2010) Kinetic studies on alcoholic fermentation under substrate inhibition conditions using a bioreactor with stirred bed of immobilized yeast cells. Open Sys Biol J 3: 9-20.

12. Matsushika A, Inoue H, Kodaki T, Sawayama S (2009) Ethanol production from xylose in engineered Saccharomyces cerevisiae strains: current state and perspectives. Appl Microbiol Biotechnol 84: 37-53.

13. Wargacki AJ, Leonard E, Win MN, Regitsky DD, Santos CN, et al. (2012) An engineered microbial platform for direct biofuel production from brown macroalgae. Science 335: 308-313.

14. Takeda H, Yoneyama F, Kawai S, Hashimoto W, Murata K (2011) Bioethano production from marine biomass alginate by metabolically engineered bacteria. Energy Environ Sci 4: 2575-2581.

15. Wang L, Sharifzadeh M, Templer R, Murphy RJ (2012) Technology performance and economic feasibility of bioethanol production from various waste papers. Energy Environ Sci 5: 5717-5730.

16. Lopez-Linares JC, Romero I, Cara C, Ruiz E, Moya M, et al. (2014) Bioethanol production from rapeseed straw at high solids loading with different process configurations. Fuel 122: 112-118.

17. Ofori-Boateng C, Lee KT (2014) Ultrasonic-assisted simultaneous saccharification and fermentation of pretreated oil palm fronds for sustainable bioethanol production. Fuel 119: 285-291.

18. Paulova L, Patakova P, Rychtera M, Melzoch K (2014) High solid fed-batch SSF with delayed inoculation for improved production of bioethanol from wheat straw. Fuel 122: 294-300.

19. Pulidindi IN, Gedanken A, Schwarz R, Sendersky E (2012) Mild sonication accelerates ethanol production by yeast fermentation. Energy Fuels 26: 2352 2356.

20. Subhedar PB, Gogate PR (2014) Alkaline and ultrasound assisted alkaline pretreatment for intensification of delignification process from sustainable rawmaterial. Ultrason Sonochem 21: 216-225.

21. Subhedar PB, Babu NR, Gogate PR (2015) Intensification of enzymatic hydrolysis of waste newspaper using ultrasound for fermentable sugar production. Ultrason Sonochem 22: 326-332.

22. Korzen L, Pulidindi IN, Israel A, Abelson A, Gedanken A (2015) Single step production of bioethanol from the seaweed Ulva rigida using sonication. RSC Adv 5: 16223-16229.

23. Birch RM, Walker GM (2000) Influence of magnesium ions on heat shock and ethanol stress responses of Saccharomyces cerevisiae. Enzyme Microb Technol 26: 678-687.

24. SivaRaman H, Chandwadkar A, Baliga SA, Prabhune AA (1994) Effect of synthetic zeolite on ethanolic fermentation of sugarcane molasses. Enzyme Microb Technol 16: 719-722. 
Citation: Tabah B, Pulidindi IN, Gedanken A (2015) Study on Fermentation Kinetics for Accelerated Production of Bioethanol from Glucose, Sucrose and Molasses. J Bioprocess Biotech 5: 232 doi:10.4172/2155-9821.1000232

25. Lee JS, Park EH, Kim JW, Yeo SH, Kim MD (2013) Growth and fermentation characteristics of Saccharomyces cerevisiae NK28 isolated from kiwi fruit. J Microbiol Biotechnol 23: 1253-1259.

26. Chiang LC, Gong CS, Chen LF, Tsao GT (1981) d-Xylulose Fermentation to Ethanol by Saccharomyces cerevisiae. Appl Environ Microbiol 42: 284-289.
27. Du Preez JC, Bosch M, Prior BA (1986) Xylose fermentation by Candida shehatae and Pichia stipitis: effects of $\mathrm{pH}$, temperature and substrate concentration. Enzyme Microb Technol 8: 360-364.

28. D'Amore T, Russell I, Stewart GG (1989) Sugar utilization by yeast during fermentation. J Ind Microbiol 4: 315-324. 